\title{
Diagnostic significance of surfactant proteins $A$ and $D$ in sera from patients with radiation pneumonitis
}

\author{
H. Takahashi*, Y. Imai*, T. Fujishima*, M. Shiratori*, S. Murakami", H. Chiba*, \\ H. Kon*, Y. Kuroki ${ }^{\#}$, S. Abe*
}

\begin{abstract}
Diagnostic significance of surfactant proteins $A$ and $D$ in sera from patients with radiation pneumonitis. H. Takahashi, Y. Imai, T. Fujishima, M. Shiratori, S. Murakami, H. Chiba, H. Kon, Y. Kuroki, S. Abe. (C)RS Journals Ltd 2001.

ABSTRACT: Radiation pneumonitis (RP) is the most common complication of radiotherapy for thoracic tumours. The aim of this study was to evaluate the significance of pulmonary surfactant proteins (SP)-A and SP-D as new serum markers for RP.

Twenty-five patients with lung tumour, who had received radiotherapy, were studied. At the completion of radiotherapy, the presence of RP was judged by chest plain radiography and chest high resolution computed tomography (HRCT).

RP findings detected on chest plain radiography were seen in only three of 12 patients in whom RP was detected by HRCT. Nevertheless, both SP-A and SP-D concentrations in sera from the patients with RP were significantly higher than those from the $\mathbf{1 3}$ patients without $\mathrm{RP}(\mathrm{p}=0.0065, \mathrm{p}=0.0011$, respectively). As with SP-A, ratios of SP$D$ at the completion, compared to at the initiation (1 week post/pre ratio), were also significantly higher in patients with RP than in patients without RP. When a post/pre ratio $>1.6$ was considered positive, the SP-A and SP-D assays showed an $83 \%$ and $85 \%$ specificity, respectively.

In conclusion, serum assays of surfactant proteins $A$ and $D$ may be of diagnostic value for detection of radiation pneumonitis, even when the radiographic change is faint. Eur Respir J 2001; 17: 481-487.
\end{abstract}

\author{
*Third Dept of Internal Medicine and \\ \#Dept of Biochemistry, Sapporo Med- \\ ical University School of Medicine, \\ Sapporo, Japan \\ Correspondence: H. Takahashi, Third \\ Dept of Internal Medicine, Sapporo \\ Medical University School of Medicine, \\ South-1 West-16, Chuo-ku, Sapporo \\ 060-8543, Japan \\ Fax: 01181116131543
}

Keywords: Radiation pneumonitis serum marker surfactant proteins

Received: April 102000

Accepted after revision September 11 2000

This study was supported by a GrantIn-Aid for Scientific Research from the Ministry of Education, Japan.
Since the lung is the major dose-limiting organ for radiotherapy in the thorax, pulmonary radiation damage is the most common complication of radiotherapy and is categorized as an interstitial lung disease (ILD) [1]. There are two well-recognized syndromes associated with pulmonary radiation damage: radiation pneumonitis (RP) and radiation fibrosis [2]. The former may indicate inflammation and sometimes lead to the latter. The major symptoms accompaning RP are fever, cough and dyspnoea, and it may occur at or near the site of radiotherapy. The incidence of RP estimated from a variety of studies is $1-34 \%$ (averaging $\sim 7 \%$ ) with symptomatic pneumonitis and $13-100 \%$ (averaging $\sim 43 \%$ ) with radiographic pneumonitis [2]. The latent period between the initiation of radiation and the development of RP is variable and most RP occurs up to $\sim 2$ months after completion of a course of radiotherapy [3]. In some cases RP involves a mild change and is self-limiting, while in others it develops into diffuse widespread pneumonitis affecting the contralateral lung, and leads to progressive respiratory insufficiency, sometimes leading to death. The latter may be of late onset and is reported to be a frequent occurrence in RP arising after radiotherapy for breast cancer $[4,5]$. Therefore, careful periodical check-ups are required for the patients receiving radiotherapy. Chest computed tomography $(\mathrm{CT})$, especially high resolution
CT (HRCT), is a gold standard for evaluating ILD [6], but it is not always possible to frequently repeat examinations by HRCT. Laboratory tests such as lactate dehydrogenase (LDH) activity are sometimes available for the detection of interstitial pneumonitis, but these markers lack organ specificity.

Hydrophilic surfactant proteins, SP-A and SP-D belong to the collectin subgroup of the C-type lectin superfamily, along with mannose-binding proteins and collectin CL43 [7]. Two types of nonciliated epithelial cells in the peripheral airways, Clara cells and alveolar type II cells, mainly produce these lung collectins $[8,9]$. An enzyme-linked immunosorbent assay (ELISA) has previously been developed for SP-A detection using anti-human SP-A monoclonal antibodies, PC6 and PE10 $[10,11]$. By using this ELISA, it has been found that SP-A molecules exist in sera and that the levels of SP-A are significantly elevated in sera from patients with idiopathic pulmonary fibrosis (IPF) $[12,13]$ and collagen vascular diseases with interstitial lung diseases (CVD-ILD) [14, 15]. By using an ELISA with antihuman SP-D monoclonal antibodies, it has also been shown that there is a prominent increase in SP-D concentrations in sera from patients with IPF and CVD-ILD [16, 17]. The determination of surfactant protein concentrations in sera provides high sensitivity and specificity markers for these ILDs. 
In this study, the concentrations of SP-A and SP-D in sera were determined from the patients with RP, which is categorized as an interstitial lung disease.

\section{Methods}

\section{Subjects}

Twenty five patients (19 males and 6 females) with lung tumours, admitted to Sapporo Medical University Hospital for definitive treatment with radiotherapy, were recruited for this study. Twenty-one of the patients were smokers. There were 13 with primary squamous cell carcinoma, 8 with primary adenocarcinoma, 3 with small cell carcinoma and one with invasive thymoma. Prior to radiotherapy, nine patients had received chemotherapy. The regimen was a combination of two or three anticancer drugs including cisplatinum. Patients with interstitial lung diseases such as IPF and CVD-ILD had been excluded as candidates prior to the selection of the 25 patients. To establish normal ranges of SP-A and SP-D, 108 healthy volunteers (42 male and 66 female, 34 current smokers and 74 nonsmokers) were also studied, ranging from $20-61$ yrs of age (mean \pm sD $56.0 \pm 10.2$ yrs).

\section{Study design}

Radiotherapy was delivered by linear accelerators. All patients received 55 Gy (range, 40-68 Gy) of median total dose; $1.8-2.5$ Gy a day, in $4-5$ fractions $w^{-} e^{-1}$. The median total period of the therapy was 7 weeks. Chest plain radiography and HRCT were performed as routine clinical evaluations at least twice; once prior to initial irradiation and then within a week after final irradiation. All images on the HRCT scan, using a GE 9800 scanner (General Electric, WI, USA), were obtained using $1.5 \mathrm{~mm}$ collimation with $10 \mathrm{~mm}$ gaps from the apex to the diaphragm in the supine position. The existence of RP was assessed on the basis of a comparison of the findings of the HRCT examinations 1 week after final irradiation and prior to initial irradiation. Serum samples were collected from all the patients three times; the first time point was prior to radiotherapy (pre-RT), the second was 1 week after the final irradiation (1 week post-RT) and the last time was 3 weeks after the final irradiation ( 3 weeks post-RT). The serum samples were stored at $-80^{\circ} \mathrm{C}$ until use for measurements of SP-A, SP-D and LDH. Blood gas analysis (BGA) was also performed when serum samples were collected and then alveolar-arterial oxygen diffusion $\left(\mathrm{A}-\mathrm{aDo}_{2}\right)$ was calculated.

\section{Measurement of surfactant protein $A$ in sera}

SP-A assay was performed according to the method of Shimizu et al. [11] with minor modifications by using ELISA kits provided from Teijin Institute of Biomedicine (Tokyo, Japan). Briefly, $50 \mu \mathrm{L}$ of standard materials containing $0-250 \mathrm{ng} \cdot \mathrm{mL}^{-1}$ of human SP-A or $50 \mu \mathrm{L}$ of serum samples, $200 \mu \mathrm{L}$ of buffer I $(10 \mathrm{mM}$ phosphate-buffered saline (PBS) at $\mathrm{pH} 7.2$ containing $1.5 \%(\mathrm{w} / \mathrm{v})$ sodium dodecyl sulphate and $3 \%(\mathrm{v} / \mathrm{v})$ Triton X-100) and $200 \mu \mathrm{L}$ of monoclonal antibody PE10 labeled with horseradish peroxidase dissolved in buffer II (10 mM phosphate-buffered saline at $\mathrm{pH} 7.4$ containing $0.25 \%(\mathrm{w} / \mathrm{v})$ skimmed milk) were mixed thoroughly. A plastic bead coated with monoclonal antibody PC6 was added to each tube containing the mixture described above. The assay tube was then incubated at $37^{\circ} \mathrm{C}$ for $90 \mathrm{~min}$. After the incubation, the beads were washed three times with saline. Four hundred microlitres of substrate solution $(0.1 \mathrm{M}$ phosphate-citrate buffer at $\mathrm{pH} 4.0$ containing $5 \mathrm{mM}$ $\mathrm{H}_{2} \mathrm{O}_{2}$ and $0.06 \%$ (w/v) tetramethylbenzidine) were added and incubated at $37^{\circ} \mathrm{C}$ for $30 \mathrm{~min}$. The reaction was finally stopped by the addition of $1 \mathrm{~mL}$ of $1 \mathrm{~N}$ sulphuric acid, and the absorbance of each tube was measured at $450 \mathrm{~nm}$. This assay system was able to detect SP-A at $2.0-250 \mathrm{ng} \cdot \mathrm{mL}^{-1}$. The monoclonal antibodies (PE10, PC6) are immunoglobulin-G2b (IgG2b) which is not affected by rheumatoid factors in general. All assays were performed in duplicate, and results were given as the mean value.

\section{Measurement of surfactant protein $B$ in sera}

SP-D ELISA kits using recombinant SP-D as a standard and two monoclonal antibodies against human SP-D were provided by Yamasa Co. (Choshi, Japan). The use of the horseradish peroxidase conjugated $F\left(a b^{\prime}\right)_{2}$ fragment gives a greater advantage for accurate detection of SP-D in sera from patients with collagen vascular disease (CVD) without interference from the rheumatoid factor [17]. Briefly, microtitre wells (Immunoplate, Maxsorp, Nunc, Denmark) were coated with $100 \mu \mathrm{L}$ of monoclonal antibody 7C6 $\left(10 \mu \mathrm{g} \cdot \mathrm{mL}^{-1}\right.$ in PBS $)$ at $4^{\circ} \mathrm{C}$ overnight. After washing three times with PBS, the wells were incubated with $200 \mu \mathrm{L}$ of PBS containing 1.0\% bovine serum albumin (BSA) at room temperature for $1 \mathrm{~h}$ to block nonspecific binding. The wells were then incubated at $4{ }^{\circ} \mathrm{C}$ overnight with $100 \mu \mathrm{L}$ of the SP-D standard solution $\left(1.56-100 \mathrm{ng} \cdot \mathrm{mL}^{-1}\right.$ of recombinant SP-D solution) or with samples diluted with $10 \mathrm{mM} \mathrm{N}$-2-hydroxyethylpiperazine-N-2-ethanesulphoric acid (HEPES) buffer, $\mathrm{pH} 7.4$, containing $150 \mathrm{mM} \mathrm{NaCl}, 0.5 \%$ Triton X100 , and $1.0 \%$ BSA (HEPES-TB). The wells were next incubated with $100 \mu \mathrm{L}$ of the horseradish peroxidase conjugated $\mathrm{F}\left(\mathrm{ab}^{\prime}\right)_{2}-6 \mathrm{~B} 2$ diluted with HEPES-TB at room temperature for $2 \mathrm{~h}$. After washing, the wells were finally incubated with $100 \mu \mathrm{L}$ of $0.3 \mathrm{mM} \mathrm{3,3',5,5^{ \prime } -}$ tetramethylbenzidine containing $0.005 \% \mathrm{H}_{2} \mathrm{O}_{2}$ at room temperature for exactly $15 \mathrm{~min}$. The reaction was terminated by adding $100 \mu \mathrm{L}$ of $1 \mathrm{~N}$ sulphuric acid and the absorbance was measured at $450 \mathrm{~nm}$. All assays were performed in duplicate, and results were given as the mean value.

\section{Statistical analysis}

Data were expressed as mean \pm SD. The upper limits of the normal ranges for SP-A and SP-D were set up at 
mean $+2 \mathrm{sD}$. The comparison of the values between the two groups, patients with and without RP, was statistically analyzed by unpaired t-test. Changes in the values from the initiation to the completion of radiotherapy were analyzed by paired t-test. Correlations were tested with Pearson's correlation test. In $2 \times 2$ tables, p-values were directly calculated by Fisher's exact probability test. p-Values $\leqslant 0.05$ were considered to be statistically significant.

\section{Results}

Twelve patients were identified with RP and 13 without RP based on the HRCT findings (table 1). The two groups were similar in age, sex and smoking habits. All 3 patients with small cell carcinoma and 5 of 8 patients with adenocarcinoma were complicated with RP, but only 3 of the 13 with squamous cell carcinoma. Prior to radiotherapy, chemotherapy by the combination of several anticancer agents including cisplatinum was given to 9 patients. Six of these 9 patients suffered RP complications; 3 with small cell carcinoma, 2 with adenocarcinoma and 1 with squamous cell carcinoma. There was no significant difference in dosage of irradiation between the two groups. No newly developed clinical symptoms associated with RP, such as a fever, had occurred at the completion of radiotherapy in $8(67 \%)$ of 12 patients with RP. No abnormal findings associated with RP could be detected by chest radiograph in $9(75 \%)$ within the group of 12 patients who showed RP complication by the chest HRCT.

At the completion of RP, serum LDH activities showed no significant differences between the two groups. In contrast, mean \pm SD SP-A and SP-D concentrations in sera from patients with RP were significantly higher than those from patients without RP (SP-A; 58.0 \pm 17.5 versus $37.6 \pm 20.8(\mathrm{p}=0.0065)$, SP-D; $145.0 \pm 44.3$ versus $78.6 \pm 31.4 \quad(\mathrm{p}=0.0011))$.
$\mathrm{A}-\mathrm{aDO}_{2}$ also showed significantly higher values in patients with RP than in those without, but its p-value $(\mathrm{p}=0.0489)$ was not smaller than those of SP-A and SPD. Their sensitivities and specificities were calculated by reference of the upper limits of the normal ranges (43.8 and $112 \mathrm{ng} \cdot \mathrm{mL}^{-1}$, respectively), which had been set up at mean $+2 \mathrm{sD} \quad\left(26.7 \pm 8.5\right.$ and $46.4 \pm 32.9 \mathrm{ng} \cdot \mathrm{mL}^{-1}$, respectively). Eight of 12 patients with RP and 3 of 13 patients without RP showed SP-A concentrations above the normal ranges. Respective sensitivities and specificities calculated from these data were $67 \%$ and $77 \%$ for SP-A, and $75 \%$ and $85 \%$ for SP-D. Accuracy of SP-A and SP-D was $73 \%$ and $82 \%$, respectively.

Changes in the markers caused by the complication of RP are shown in figure 1 . Eleven of the 12 patients with RP showed significant increases $(p<0.0001$ by paired t-test) in both SP-A and SP-D. However, 6 of these 12 did not show increases in $\mathrm{A}-\mathrm{aDO}_{2}$ or in $\mathrm{LDH}$. Two patients and one patient showed respective SP-A and SP-D levels above the upper limits of normal at the initiation of radiotherapy. This elevation may reflect subcritical microdisturbance in the lung, caused by anticancer drugs, which could not be detected on HRCT.

Among the 13 patients without RP, 9 and 11 showed increments in SP-A and SP-D levels, respectively, following completion of radiotherapy. These changes were statistically significant only for SP-D $(p=0.0315)$. However, when the elevation rates of SP-A and SP-D were calculated and expressed as a "1 week post/pre ratio", significant changes became evident. The week post/pre ratio in SP-A and SP-D was significantly greater in patients with RP than in patients without it (SP-A; $1.71 \pm 0.34$ versus $1.19 \pm 0.41(\mathrm{p}=0.002)$, SP-D; $2.18 \pm 0.53$ versus $1.3 \pm 0.5(\mathrm{p}=0.0003)$, respectively $)$ (fig. 2 ). When a 1 week post/pre ratio of more than 1.6 was considered as positive (table 2), both the SP-D and SP-A assays showed an $83 \%$ sensitivity and an $85 \%$ specificity, with positive and negative predictive values

Table 1. - Characteristics of the 25 radiotherapy patients

\begin{tabular}{|c|c|c|c|}
\hline Characteristics & Presence of RP $(n=12)$ & Absence of RP $(n=13)$ & p-value \\
\hline Age, yrs & $65.7 \pm 12.4$ & $64.5 \pm 11.2$ & NS \\
\hline Male/female & $8 / 4$ & $11 / 2$ & NS \\
\hline Smoker/nonsmoker & $11 / 1$ & $10 / 3$ & NS \\
\hline \multicolumn{4}{|l|}{ Histology } \\
\hline Squamous cell carcinoma & 3 & 10 & \\
\hline Small cell carcinoma & 3 & 0 & \\
\hline Adenocarcinoma & 5 & 3 & \\
\hline Invasive thymoma & 1 & 0 & \\
\hline Preceding anticancer agents & 6 & 3 & NS \\
\hline Total dose, Gy & $56.0 \pm 5.4$ & $52.7 \pm 6.2$ & NS \\
\hline New symptom at the completion of $\mathrm{RT}^{\#}$ & 4 & 0 & \\
\hline $\mathrm{RP}$ on plain radiography ${ }^{\#}$ & 3 & 0 & \\
\hline RP on HRCT & 12 & 0 & \\
\hline $\mathrm{LDH}^{\#} \mathrm{IU} \cdot \mathrm{L}^{-1}$ & $291.6 \pm 83.9$ & $283.0 \pm 61.8$ & NS \\
\hline 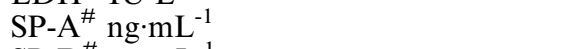 & $58.0 \pm 17.5$ & $37.6 \pm 20.8$ & 0.0065 \\
\hline $\mathrm{SP}-\mathrm{D}^{\#} \mathrm{ng} \cdot \mathrm{mL}^{-1}$ & $145.0 \pm 44.3$ & $78.6 \pm 31.4$ & 0.0011 \\
\hline $\mathrm{A}-\mathrm{aDO}_{2}{ }^{\#-} \mathrm{mmHg}$ & $22.4 \pm 11.4$ & $13.9 \pm 6.4$ & 0.0489 \\
\hline
\end{tabular}

Values are $\mathrm{n}$ or mean \pm SD. ${ }^{\#}$ : values were obtained 1 week after the completion of radiotherapy. The normal upper limits of SP-A, SP-D and LDH were $43.8 \mathrm{ng} \cdot \mathrm{mL}^{-1}, 112 \mathrm{ng} \cdot \mathrm{mL}^{-1}$ and $440 \mathrm{IU} \cdot \mathrm{L}^{-1}$, respectively. RP: radiation pneumonitis; HRCT: high resolution computed tomography; $\mathrm{LDH}$ : lactate dehydrogenase; SP: surfactant protein; A-aDo $\mathrm{o}_{2}$ : alveolar-arterial oxygen diffusion; NS: nonsignificant. Statistical analysis was performed by Fisher's exact probability test and unpaired t-test. 

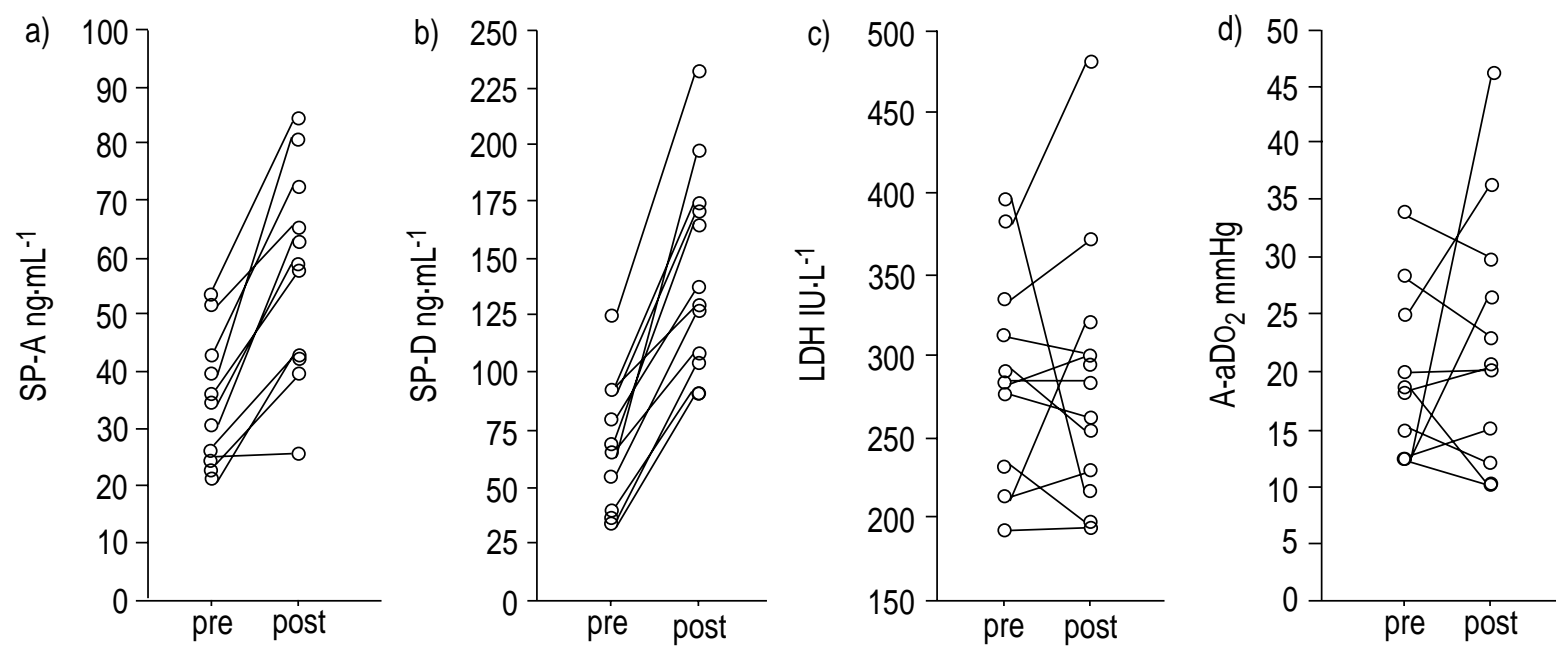

Fig. 1. - Serum a) Surfactant Protein-A (SP-A) and b) Surfactant Protein-D (SP-D) concentrations, c) serum lactate dehydrogenase $(\mathrm{LDH})$ activity, and d) alveolar-arterial oxygen diffusion $\left(\mathrm{A}-\mathrm{aDO}_{2}\right)$ at the initiation (pre) and at one week after completion (post) of radiotherapy in 12 patients with RP. Significant differences from "post" to "pre" were observed in SP-A and SP-D ( $<<0.0001$ by a paired t-test).

of $83 \%$ and $85 \%$, respectively. The relative risk for the complication in the presence of both assay's 1 week post/pre ratios of greater than 1.6, was 5.4. When SP-A and SP-D assays were combined, a high sensitivity ( $92 \%$ (11 out of 12)) was obtained for detection of RP by HRCT (table 2). As shown in figure 3, serum concentrations of SP-A and SP-D at the completion of radiotherapy in each patient were statistically correlated $(\mathrm{r}=0.424, \mathrm{p}=0.034)$. When assessed by the 1 week post/pre ratio, the correlation coefficient became higher $(\mathrm{r}=0.778, \mathrm{p}<0.0001)$ (fig. 3$)$. These results indicate that the elevations in serum concentrations of SP-A and SP-D, especially when estimated as their 1 week post/pre ratios, are closely associated with the presence of RP.

Of 12 patients with RP, seven who had symptoms and/or relatively apparent CT findings, received systemic glucocorticoid therapy at or within a week after 1 week post-RT. This therapy was effective and resulted in the improvement of symptoms and radiological changes in all cases. Concentrations of SP-A and SP-D measured at 3 weeks post-RT were $32.1 \pm 13.4$ and $72.3 \pm 12.1 \mathrm{ng} \cdot \mathrm{mL}^{-1}$, respectively, in the steroid-treated patients. These values were significantly lower $(\mathrm{p}=0.0137$ and $\mathrm{p}=0.0009$, respectively) than those in the same patients $\left(52.3 \pm 20.9 \mathrm{ng} \cdot \mathrm{mL}^{-1}\right.$ and $143.6 \pm 38.8 \mathrm{ng} \cdot \mathrm{mL}^{-1}$, respectively) at 1 week postRT before commencement of steroids. On the other hand, 3 of the 5 nontreated patients showed a persistent elevation of SP-A and SP-D and a continuance of mild RP at 3 weeks post-RT. Mean values of SP-A $\left(46.6 \pm 12.9 \mathrm{ng} \cdot \mathrm{mL}^{-1}\right)$ and SP-D $\left(133.3 \pm 28.5 \mathrm{ng} \cdot \mathrm{mL}^{-1}\right)$ at 3 weeks post-RT showed no significant difference from those at 1 week post-RT $(56.2 \pm 13.4$ and
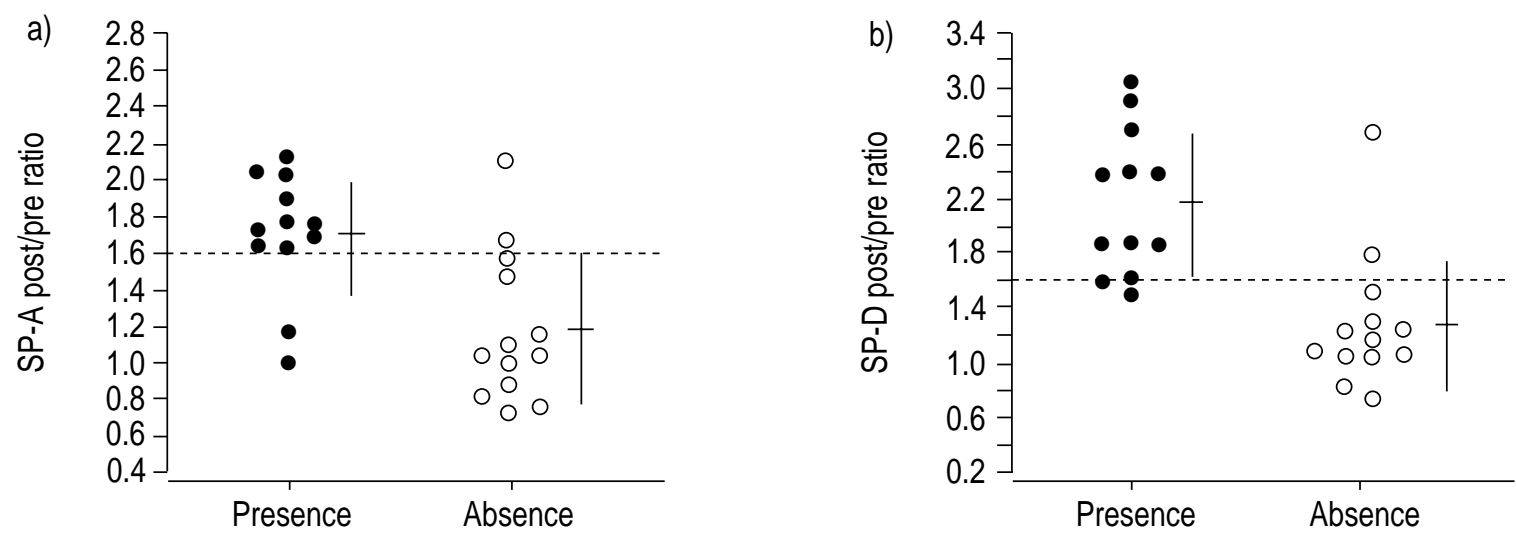

Fig. 2. - The ratios of concentrations at one week after completion of radiotherapy compared to those at the initiation of radiography (1 week post/pre ratio) are plotted. The ratios of a) surfactant protein (SP) A and b) SP-D in patients with radiation pneumonitis (RP) show significantly higher values than those in patients without RP ( $p=0.002$ for SP-A and $p=0.0003$ for SP-D). Bars represent the mean $\pm S D$. Each dashed line represents the cut-off level (1.6). 
Table 2. - Surfactant protein-A (SP-A) and Surfactant protein-D (SP-D) 1 week post/pre ratios in patients who received radiotherapy

\begin{tabular}{|c|c|c|c|c|}
\hline & Presence of RP & Absence of RP & Total & \\
\hline \multicolumn{5}{|l|}{ Ratio* of } \\
\hline $\mathrm{SP}-\mathrm{A} \geqslant 1.6^{\S}$ & 10 & 2 & 12 & Sensitivity: $83 \%$ \\
\hline SP-A $<1.6$ & 2 & 11 & 13 & Specificity: $85 \%$ \\
\hline Total & 12 & 13 & 25 & PPV: $83 \%$ \\
\hline Ratio* of & & & & NPV: $85 \%$ \\
\hline SP-D $\geqslant 1.6^{\S}$ & 10 & 2 & 12 & Sensitivity: $83 \%$ \\
\hline SP-D $<1.6$ & 2 & 11 & 13 & Specificity: $85 \%$ \\
\hline Total & 12 & 13 & 25 & PPV: $83 \%$ \\
\hline Ratio $^{\S}$ of & & & & NPV: $85 \%$ \\
\hline SP-A and/or SP-D $\geqslant 1.6^{\S}$ & 11 & 3 & 14 & Sensitivity: $92 \%$ \\
\hline SP-A and SP-D $<1.6$ & 1 & 10 & 11 & Specificity: $77 \%$ \\
\hline Total & 12 & 13 & 25 & $\begin{array}{r}\text { PPV: } 79 \% \\
\text { NPV: } 91 \%\end{array}$ \\
\hline
\end{tabular}

*: serum concentration $\left(\mathrm{ng} \cdot \mathrm{mL}^{-1}\right)$ one week after the completion of radiation therapy/serum concentration $\left(\mathrm{ng} \cdot \mathrm{mL}^{-1}\right)$ at the initiation of radiation therapy. PPV: positive predictive value; NPV: negative predictive value; RP: radiation pneumonitis; s: $\mathrm{p}<0.005$ using Fisher's exact test.

$147.0 \pm 56.0 \mathrm{ng} \cdot \mathrm{mL}^{-1}$, respectively). The declining rates of SP-A and SP-D were calculated and expressed as "3 weeks post/1 week post ratio". The ratios of SP-A in the glucocorticoid-treated RP patients $(0.58 \pm 0.24)$ were smaller than those in the nontreated $\bar{R} P$ patients $(0.83 \pm 0.14)$. A similar difference between the two groups was seen in the ratios of SP-D $(0.52 \pm 0.10$ versus $0.99 \pm 0.32)$ and the difference was significant $(\mathrm{p}=0.0045)$.

\section{Discussion}

Some haematological laboratory markers such as serum LDH activity, $\mathrm{A}-\mathrm{aDO}_{2}$ and soluble intercellular adhesion molecule-1 [18] are available for the detection of RP, although these markers are not organ specific. In this study, the conventional haematological markers were compared with new serum markers, SP-A and SP$\mathrm{D}$. When the markers were simultaneously measured at the completion of radiotherapy, the concentrations of
SP-A and SP-D in sera from patients who had the complication of RP were significantly higher than those from patients without RP, while serum LDH activity did not show a significant difference between them. Although $\mathrm{A}-\mathrm{aDO}_{2}$ was also elevated in patients with $\mathrm{RP}$, the p-value (0.0489) was clearly at a lower level of significance than that of SP-A and SP-D (0.0065 and 0.0011 , respectively). In patients with RP detected by HRCT, the majority revealed no symptoms (67\%) and no radiographic abnormalities $(75 \%)$ associated with RP, suggesting that their lung damage was mild. Nevertheless, elevated levels of serum SP-A and SP-D, unlike LDH, were observed at the completion of radiotherapy. Moreover, SP-A and SP-D showed significantly elevated changes, which were not observed for $\mathrm{LDH}$ or $\mathrm{A}-\mathrm{aDO}_{2}$ between the initiation and the completion of radiotherapy. These results demonstrate that the elevated levels of SP-A and SP-D in sera can accurately reflect even mild damage in irradiated lungs.

Even in the absence of RP, several patients exhibited
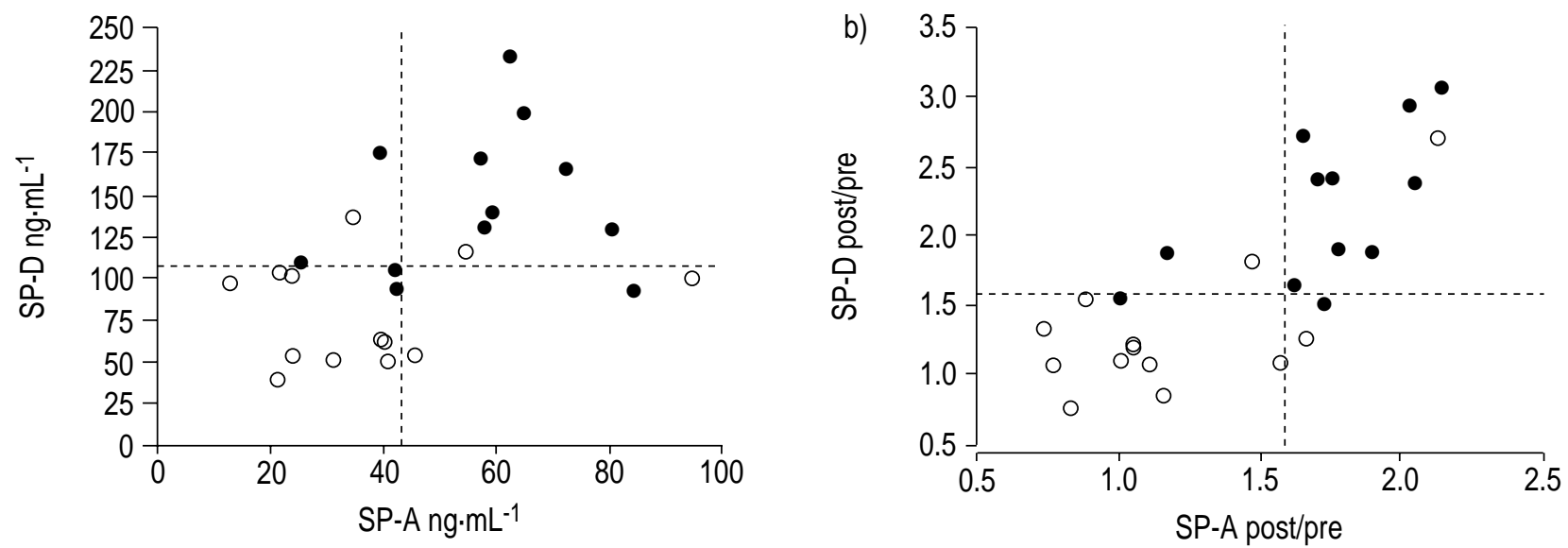

Fig. 3. - Scatter plot showing a) the relationship between surfactant protein $(\mathrm{SP})-\mathrm{A}$ and $\mathrm{SP}-\mathrm{D}$ concentrations $(\mathrm{r}=0.424$, $\mathrm{p}=0.034)$, and b) the relationship between SP-A and SP-D 1 week post/pre ratios $(r=0.778, p=0.0001)$ in patients with radiation pneumonitis $(\mathrm{RP})$ (closed circles) and patients without RP (open circles). 
increases of serum concentrations of SP-A and SP-D between the initiation and the completion of radiotherapy. Unlike with SP-A, the increase in SP-D was significant $(p=0.0315)$. This result suggests that SP-D reflects a mild degree of lung damage by irradiation better than SP-A. However, this elevation may be an obstacle to the discrimination of critical RP from mild damage. To prevent over diagnosis, the 1 week post/pre ratios were calculated and their application was evaluated. SP-A ratio showed a significant difference between patients with RP and those without it. SP-D ratio also showed a significant difference between them. When the ratios were divided into those above or below the upper limit of normal at a value of 1.6, this cut-off level had a positive predictive value of $83 \%$ and a negative predictive value of $85 \%$ for SP-A; values which were equal to those of SP-D. One week post/pre ratios of more than 1.6 for SP-A were associated with a relative risk of 5.4, which was equal to the relative risk by 1 week post/pre ratios for SP-D. In the patients studied, a significantly positive correlation was observed between concentrations of SP-A and SP-D, and in a comparative evaluation of their 1 week post/ pre ratios, the correlation coefficient was extremely high $(\mathrm{r}=0.778, \mathrm{p}<0.0001)$. This result may support the validity of the 1 week post/pre ratio as a tool for judging the onset of RP. The above findings suggest that assays for SP-A and SP-D may be valuable tools for the detection of RP.

Since this study was a short term project over 3 weeks after the completion of radiotherapy, no information was collected about longer-term follow up. Therefore, it remains to be determined whether measurements of SPA and SP-D will be effective for the detection of RP at late onset. In the future, a prospective study including serial measurements is needed to determine whether there is a relationship between these values and the subsequent development of symptomatic pneumonitis, especially diffuse widespread pneumonitis.

As a powerful strategy against nonoperative lung cancer, radical radiotherapy with concurrent chemotherapy has been earnestly tried [19], resulting in an increase in the incidence of RP and mortality due to RP $[19,20]$. In this study, the incidence of RP was higher in patients who underwent chemotherapy prior to radiotherapy ( 6 out of $9,67 \%$ ) than in those who did not (6 out of 16, 38\%). For these reasons, SP-A and SP-D may be helpful markers to assist in the management of patients who are receiving concurrent chemotherapy. The radiographic manifestations of $\mathrm{RP}$ are occasionally obscured by tumour shadow, atelectasis and infectious pneumonia, or when the shadow develops behind the mediastinum. In previous studies $[12,13]$, there were no significant increases of SP-A and SP-D in sera form patients with infectious pneumonia. In these circumstances, serial assays of SP-A and SP-D may function as meaningful screening tests prior to evaluation by HRCT.

In this study, patients who received systemic glucocorticoid therapy showed a clearer decline in concentrations of SP-A and SP-D than the non-treated patients, in agreement with clinical improvement. The occasional efficacy of corticosteroids against RP has been reported, but severe or well-established cases may be refractory to even very high doses of corticosteroid therapy [21]. Initiation of the therapy as early as possible helps to prevent progression to an advanced stage of RP. On the basis of this conception, serial assays of SP-A and SP-D can prevent clinicians from overlooking the early stage of lung damage, at which the corticosteroid therapy is still effective.

Alteration of the surfactant system is one of the earliest detectable changes following lung irradiation [22]. In patients with RP, saturated phosphatidylcholine, an essential lipid component for surfactant function, decreases according to the progression as shown by radiography [22]. This alteration in the surfactant system may cause a collapse of alveoli and result in fibrosis. SP-A levels in epithelial lining fluid (ELF) were also decreased after irradiation, and the concentrations showed a negative correlation to the severity of radiographic changes [22]. Previous studies indicated that both SP-A and SP-D decreased in ELF while increasing in sera, from patients with IPF $[12,13$, $16,23]$. These changes in IPF were similar to those in $\mathrm{RP}$, suggesting that a similar pathologic process between IPF and RP relate to their leakage which is accelerated as a result of damage to the air-blood barrier in lung parenchyma. According to a three-poresize model used by ConHAIM et al. [24], a very small number of the largest pores ( $800 \mathrm{~nm}$ pore diameter) exist on the barrier in a physiologically steady state. Both SP-A and SP-D, with diameters of approximately $20 \mathrm{~nm} \mathrm{[25]} \mathrm{and} 100 \mathrm{~nm}$ [26], respectively, can be pressumably transferred across the pores. This theory appears to explain the appearance of small amounts of SP-A and SP-D in healthy subjects. In a pathological state, focal defects, irregular thickening, complex folding and reduplication of alveolar basement membranes are seen in lung tissue from patients with diffuse alveolar damage and IPF [27]. Similar damage to the air-blood barrier is seen ultrastructually in irradiated mice [28]. It is therefore assumed that the damage to basement membranes is in part involved in the mechanisms of the leakage. Moreover, the leakage might be dependent on the degree of assembly of SP-A and SP-D, since the state of the assembled forms of these molecules may vary between individuals [29]. Additionally, it is possible that SP-A and SP-D derived from other organs might contribute to the elevations in serum concentrations, since these proteins are also expressed in organs such as the stomach and small intestine. To confirm these assumptions, further studies are required.

In conclusion, the serum assays of surfactant proteins A and D may provide a diagnostic tool of value for detection of radiation pneumonitis even when its radiographic change is faint.

\footnotetext{
Acknowledgements. The authors wish to thank Dr. Y. Honda (Sapporo NTT Hospital), Dr. M. Hareyama (Dept of Radiology, Sapporo Medical University School of Medicine) and Dr. Akino (Sapporo Medical University) for valuable suggestions and encouragement.
} 


\section{References}

1. Schwarz MI. Clinical overview of interstitial lung disease. In: Schwartz MI and King TE Jr., eds. Interstitial Lung Disease. St. Lois, Mosby, 1993; $1-$ 22.

2. Movsas B, Raffin TA, Epstein AH, Link CJ Jr. Pulmonary radiation injury. Chest 1997; 111: 1061 1076.

3. Rosenow EC III, Martin WJ II. Drug-induced interstitial lung disease. In: Schwartz MI and King TE Jr., eds. Interstitial Lung Disease. Mosby, St. Lois, MO: 1993; 255-270.

4. Martin C, Romero S, Sanchez-Paya J, Massuti B, Arriero JM, Hernandez L. Bilateral lymphocytic alveolitis: a common reaction after unilateral thoracic irradiation. Eur Respir J 1999; 13: 727-732.

5. Prakash USB. Radiation-induced injury in the 'nonirradiated' lung. Eur Respir J 1999; 13: 715-717.

6. Muller NL, Miller RR. Computed tomography of chronic diffuse infiltrative lung disease. Part 1. Am Rev Respir Dis 1990; 142: 1206-1215.

7. Day AJ. The C-type carbohydrate recognition domain (CRD) superfamily. Biochem Soc Trans 1994; 22: 83 88 .

8. Walker SR, Williams MC, Benson B. Immunocytochemical localization of the major surfactant apoprotein in type II cells, Clara cells and alveolar macrophages of rat lung. J Histochem Cytochem 1986; 34: $1137-1148$.

9. Voorhout WF, Veenendaal T, Kuroki Y, Ogasawara Y, van Golde LMG, Geuze HJ. Immunocytochemical localization of surfactant protein (SP-D) in type II cells, Clara cells, and alveolar macrophages of rat lungs. J Histochem Cytochem 1992; 40: 1589-1597.

10. Kuroki Y, Fukada Y, Takahashi H, Akino T. Monoclonal antibodies against human pulmonary surfactant apoproteins: specificity and application in immunoassay. Biochim Biophys Acta 1985; 836: $201-209$.

11. Shimizu H, Hosoda K, Mizumoto M, et al. Improved immunoassay for the determination of surfactant protein A (SP-A). Tohoku J Exp Med 1989; 157: $269-278$.

12. Kuroki Y, Tsutahara S, Shijubo N, et al. Elevated levels of lung surfactant protein A in sera from patients with idiopathic pulmonary fibrosis and pulmonary alveolar proteinosis. Am Rev Respir Dis 1993; 147: $723-729$.

13. Honda Y, Kuroki Y, Shijubo N, et al. Aberrant appearance of lung surfactant protein $\mathrm{A}$ in sera of patients with idiopathic pulmonary fibrosis and its clinical significance. Respiration 1995; 62: 64-69.

14. Takahashi H, Honda Y, Kuroki Y, Imai Y, Abe S. Pulmonary surfactant protein A: a serum marker of pulmonary fibrosis in patients with collagen vascular diseases. Clin Chim Acta 1995; 239: 213-215.

15. Takahashi H, Kuroki Y, Tanaka H, et al. Serum
Levels of Surfactant Proteins A and D are useful biomarkers for interstitial lung disease in patients with progressive systemic sclerosis. Am J Respir Crit Care Med 2000; 162: 258-263.

16. Honda Y, Kuroki Y, Matuura E, et al. Pulmonary surfactant protein $\mathrm{D}$ in sera and bronchoalveolar lavage fluids. Am J Respir Crit Care Med 1995; 152: $1860-1866$.

17. Nagae H, Takahashi H, Kuroki Y, et al. Enzymelinked immunosorbent assay using $\mathrm{F}\left(\mathrm{ab}^{\prime}\right) 2$ fragment for the detection of human pulmonary surfactant $\mathrm{D}$ in sera. Clin Chim Acta 1997; 266: 157-171.

18. Ishii Y, Kitamura S. Soluble intercellular adhesion molecule-1 as an early detection marker for radiation pneumonitis. Eur Respir J 1999; 13: 733 - 738.

19. Lebeau B, Urban T, Jbrechot JM, et al. A randomized clinical trial comparing concurrent and alternating thoracic irradiation for patients with limited small cell lung carcinoma. Cancer 1999; 86: 1480-1487.

20. Segawa Y, Takigawa N, Kataoka M, Takata I, Fujimoto N, Ueoka H. Risk factors for development of radiation pneumonitis following radiation therapy with or without chemotherapy for lung cancer. Int J Radiat Oncol Biol Phys 1997; 39: 91 -98.

21. Smith JC. Radiation pneumonitis. Am Rev Respir Dis 1963; 87: 647-655.

22. Hallman M, Maasilta P, Kivisaari L, Mattson K. Changes in surfactant in bronchoalveolar lavage fluid after hemithorax irradiation in patients with mesothelioma. Am Rev Respir Dis 1990; 141: $998-$ 1005.

23. McCormack FX, King TE Jr, Bucher BL, Nielsen L, Mason RJ. Surfactant protein A predicts survival in idiopathic pulmonary fibrosis. Am J Respir Crit Care Med 1995; 152: 751 - 759 .

24. Conhaim RL, Eaton A, Staub NC, Heath TD. Equivalent pore estimate for the alveolar-airway barrier in isolated dog lung. J Appl Physiol 1988; 64: $1134-1142$.

25. Voss T, Eistetter H, Schafer KP, Engel J. Macromolecular organization of natural and recombinant lung surfactant protein SP $28-36$. Structural homology with the complement factor C1q. J Mol Biol 1988 201: 219-227.

26. Crouch E, Persson A, Chang D, Heuser J. Molecular structure of pulmonary surfactant protein D (SP-D). J Biol Chem 1994; 269: 17311-17319.

27. Kawanami O, Ferrans VJ, Crystal RG. Structure of alveolar epithelial cells in patients with fibrotic lung disorders. Lab Invest 1982; 46: 39-53.

28. de Saint-Georges L, Van Gorp U, Maisin JR. Response of mouse lung air-blood barrier to Xirradiation: ultrastructural and stereological analysis. Scanning Microsc 1988; 2: 537-543.

29. Hickling TP, Malhotra R, Sim RB. Human lung surfactant protein A exists in several different oligomeric states: oligomer size distribution varies between patient groups. Mol Med 1998; 4: 266-725. 